\title{
Evolution of blood pressure in children with congenital and acquired solitary functioning kidney
}

\author{
Riccardo Lubrano ${ }^{1 *}$, Isotta Gentile ${ }^{1}$, Raffaele Falsaperla², Giovanna Vitaliti', Alessia Marcellino ${ }^{1}$ and Marco Elli ${ }^{3}$
}

\begin{abstract}
Background: It is not yet clear if blood pressure and renal function changes evolve differently in children with a congenital or acquired solitary functioning kidney. This study aims to assess if there are any differences between these two types of solitary kidney patients.

Methods: Current research is a retrospective study assessing the evolution of glomerular filtration rate, proteinuria, and blood pressure in clinical records of 55 children with a solitary functioning kidney (37 congenital and 18 acquired). We used the medical records of children who had been assisted, in our unit of pediatric nephrology, for a period of 14 years (168 months), from the time of diagnosis, between January/1997 and December/2015.

Results: During the study period, glomerular filtration rate (T0 $128.89 \pm 32.24$ vs T14 $118.51 \pm 34.45 \mathrm{ml} / \mathrm{min} / 1$. $73 \mathrm{~m}^{2}, \mathrm{p} \mathrm{NS}$ ) and proteinuria (T0 $85.14 \pm 83.13$ vs T14 $159.03 \pm 234.66 \mathrm{mg} / \mathrm{m}^{2} /$ die, p NS) demonstrated no significant change. However, after 14 years of follow-up $76.4 \%$ of patients had increased levels of arterial hypertension with values over the 90th percentile for gender, age, and height. Specifically, children with an acquired solitary functioning kidney mainly developed hypertension [T0 2/17 (12\%) vs T14 9/17 (52.9\%) $p<0.025]$, whereas children with a congenital solitary functioning kidney mainly developed pre-hypertension [T0 3/38 (7.9\%) vs T14 17/38 (44.7\%) $p<0.0005]$.

Conclusions: The renal function of children with solitary functioning kidneys remains stable during a follow-up of 14 years. However, these children should be carefully monitored for their tendency to develop arterial blood pressure greater than the 90th percentile for gender, age, and height.
\end{abstract}

Keywords: Solitary functioning kidney, Glomerular filtration rate, Renal scar, Hypertension, Pre-hypertension, Blood pressure

\section{Background}

In the 1980s, Brenner et al. [1-3] theorized, based on observational animals models, that the compensatory hypertrophy of the solitary functioning kidney (SFK) would cause hyperfiltration in the residual nephrons; leading to proteinuria and arterial hypertension and finally glomerulosclerosis and End Stage Renal Disease (ESRD) would happen. Human studies in SFK patients reported conflicting results. Siomou et al. [4] reported an increase of blood pressure Z-score values; while renal function and microalbumin urinary excretion were

\footnotetext{
*Correspondence: riccardo.lubrano@uniroma1.it

${ }^{1}$ Pediatric Department, Pediatric Nephrology Unit, Sapienza University of

Rome, Viale Regina Elena 324, 00161 Rome, Italy

Full list of author information is available at the end of the article
}

normal among congenital SFK children compared to control group. Contradictory, Dursun et al. [5] found a reduced renal function accompanied with normal blood pressure. While Shirzai et al. [6] found increased levels of 24-h urinary microalbumin only in children suffering from SFK with longer than 5-year duration since onset. On the other hand, Seeman et al. [7] reported blood pressure increase and reduced renal function in SFK children with abnormalities of their residual kidney.

Therefore, Siomou [4] highlighted the importance of increased serial controls in case of glomerular hyperfiltration signs; whereas Shirzai [6] supported clinical controls for the possible onset of microalbuminuria, only for subjects suffering from SFK for more than 5 years. Finally, 
Seeman [7] recommended strict clinical observation only for children with SKF and renal scarring.

Present study conducted a retrospective approach in a population of SFK children, in order to assess changes in renal function (glomerular filtration rate and proteinuria) and arterial blood pressure according to the congenital or acquired nature of the diseases. Patients were followed over a 168-month observation period.

\section{Methods}

\section{Study population}

This is a retrospective study based on the clinical records of pediatric patients with congenital or acquired SFK, with an observation time of 14 years (168 months). Current study aimed to assess if the nature of SFK (congenital vs. acquired) has a different influence on blood pressure and renal function.

\section{Inclusion and exclusion criteria}

We enclosed all children referred to our center with a diagnosis of SFK that were aged between 3 months and 18 years at diagnosis; and followed them at our day hospital for 14 years. SFK subjects were divided into two groups: congenital SFK (cSFK) and acquired SFK (aSFK).

The cSFK group included patients with one kidney found absent or significantly smaller at ultrasound, with no detectable renal function or glomerular filtration rate (GFR) $<10 \mathrm{ml} / \mathrm{min} / 1.73 \mathrm{~m}^{2}$ at Tc-99 $\mathrm{m}$ DTPA renal scintigraphy, and no history of surgical nephrectomy.

The aSFK group included SFK patients with complete absence of one kidney due to previous mono-lateral total nephrectomy due to trauma.

Exclusion criteria included previous treatment with drugs potentially affecting renal function, documented orthostatic proteinuria, congenital anomalies of the urinary tract and SFK due to previous nephrectomy for causes other than trauma.

\section{Protocol of the study}

For each patient, glomerular filtration rate, proteinuria, and blood pressure at the time of first admission (T0) and at 14 years (T14) were extrapolated from the records stored in our center for pediatric nephrology.

1) For the evaluation of renal function

- We measured proteinuria in 24-h urine collections as described previously [8]. In case of lack of voluntary control of micturition, we collected the urine for $8 \mathrm{~h}$ in daytime via urinary collection bags connected to a binder (U-Bag ${ }^{\oplus}$ Urine Specimen Collector).

- We used the Tc-99 m DTPA renal scintigraphy to measure the GFR of the two kidneys separately
[9] and Tc-99 m DMSA renal scintigraphy to detect the presence of renal scars [10]

- As normal values, we assumed: GFR >90 ml/ $\mathrm{min} / 1.73 \mathrm{~m}^{2}[11,12]$ and proteinuria $<100 \mathrm{mg} /$ $\mathrm{m}^{2} / 24 \mathrm{~h}$ [13].

2) Measurement, evaluation, and classification of blood pressure:

In children $<120 \mathrm{~cm}$ in height we only took blood pressure manually with a mercury sphygmomanometer (clinical blood pressure). In children $\geq 120 \mathrm{~cm}$ in height we added a 24-h ambulatory blood pressure monitoring (ABPM) applying the technical modalities described previously [14]. For all blood pressure measures we used a cuff appropriate to the size of the child's upper arm according to the Fourth Report [15]. To classify the blood pressure status of the children we used centiles and the classification schemes of the following guidelines :

- In children between 0 and 18 years:

- Clinical blood pressure classification:

- In children less than 1 year, the tables for diagnosis of neonatal hypertension were used [16]

- In children between 1 and 18 years, we used "the Fourth Report on the Diagnosis, Evaluation and Treatment of High Blood Pressure in Children and Adolescents" [15]. as it separates 1) normal blood pressure, 2) hypertension, and 3) prehypertension.

- ABPM classification:

- The updated recommendations for the standard assessment of ABPM in children and adolescent were applied [17] which combines clinical blood pressure and ABPM value

- as it separates 1) normal blood pressure, 2) hypertension, and 3) prehypertension, 4) masked hypertension, and 5) with white coat hypertension

- In patients older than 18 years:

- The guidelines set by the European Society of Cardiology for the assessment of clinical blood pressure and ABPM were followed [18].

- as it separates adults with In 1) normal blood pressure, 2) hypertension, and 3) prehypertension, 4) masked hypertension, and 5) with white coat hypertension

\section{Ethical considerations}

The study protocol conformed to the ethical guidelines of the 1975 Declaration of Helsinki as revised in 2000 [19] and was approved by the ethic committee of our institutions. 


\section{Statistical analysis}

For statistical evaluation, we used a dedicated software: JMP (produce of SAS Institute Inc. Cary, NC 27513-2414, USA) e GraphPad 5.0 (La Jolla, CA, U.S.A.). We expressed the qualitative variables as percent and the quantitative as mean \pm standard deviation. We analyzed the differences between the groups using the chi-square $\left(\chi^{2}\right)$ test for data expressed as percent. For the data expressed as mean \pm standard deviation we tested the approximation to normal of the distribution of the population by KolmogorovSmirnov One-Sample Test and statistics for kurtosis and symmetry. As results were asymmetrically distributed, non-parametric tests were used (Wilcoxon test).

We considered the differences with $p<0.05$ significant.

\section{Results}

\section{Characteristics of the study population}

We examined the clinical records of 61 patients (44 males and 17 females) during 14 years after diagnosis at our center. Among them, 6 patients were excluded. Two of them had nephrectomy secondary to Wilms tumor, and four were affected by vesicoureteral reflux. Among remaining 55 patients (40 males and 15 females), 38 patients had congenital SFK and 17 of them experienced acquired form.

The mean age at diagnosis was significantly lower $(p<0.001)$ in the cSFK group $(6.24 \pm 3.55$ months $)$ compared to the aSFK group ( $95.11 \pm 33.12$ months). Causes of cSFK included unilateral renal agenesis in 21 , congenital aplasia/hypoplasia in 8 , and multicystic kidney disease in 9 children.

\section{Renal function}

In Table 1 we report mean values of GFR and proteinuria in total population, and their mean values in each of the two subgroups (aSFK and cSFK) at T0 and T14. No significant differences between these groups were detected.

The number of subjects with renal scar was similar at T0 in both groups (cSFK 10/38 vs aSFK 4/17 p NS); while it was significantly increased at T14 in subjects with cSFK (T0 10/38 vs T14 24/38 $p<0.003$ ). This value remained stable in aSFK patients during the course of follow-up (T0 4/17 vs T14 5/17 p NS).

\section{Hypertension}

Table 2 illustrates the partition of SFK patients congenital and acquired in normotensive, prehypertensive, and hypertensive at $\mathrm{T} 0$ and $\mathrm{T} 14$.

At T0, blood pressure was above the 90th centile in 12 children (22\%), equally divided between prehypertensive (11\%) and hypertensive (11\%). At T14 (end of the study period) the number of children with blood pressure $>90$ th centile had increased to $42(76.4 \%)$ (T0 vs T14 $p<0.0001$ ); which $22(40 \%)$ of them were prehypertensive and 20 (36.4\%) were hypertensive (Table 2). Particularly, there was a significant increase of prehypertension (PreHyp) in the cSFK group (T0 $3 / 38$ vs T14 17/38 $p<0.0005)$, as well as a significant increase of hypertension (Hyp) in the aSFK group (T0 2/17 vs T14 9/17 $p<0.025$ ) (Table 2).

In particular, subjects with renal scars and hypertension where distributed as follows:

- Acquired solitary functioning kidney, $1 / 17$ at T0 and 2/ 17 at T14 (i.e., $1 / 2$ hypertensive at T0 and 2/9 at T14)

- Congenital solitary functioning kidney, $2 / 38$ at T0 and $9 / 38$ at T14 $p<0.047$ (i.e., $2 / 4$ hypertensive at T0 and $9 / 11$ at T14)

In our study we did not detect any subjects with masked hypertension or white coat hypertension.

\section{Discussion}

Current study showed that during a 168-month follow up of children with congenital or acquired solitary functioning kidney, renal functions did not change significantly and blood pressure increased up to over the 90th centile in $76.4 \%$ of the studied population. These findings are in agreement with the results of Siomou et al. [4], but in contrast with other reports $[5,6]$ outlining an alteration of the renal function and/or normal blood pressure values. In our study, children with high blood pressure have apparently normal renal function. What we found, may also be due to the fact that, as described in the literature, nearly $50 \%$ of SFK patients have a reduced renal functional reserve [20]: this might help to explain why it is possible to observe the development of high blood pressure

Table 1 GFR and proteinuria at time of diagnosis (T0) and after 14 years follow-up (T14)

\begin{tabular}{|c|c|c|c|c|c|c|}
\hline & \multicolumn{3}{|c|}{$\begin{array}{l}\text { GFR } \\
\mathrm{ml} / \mathrm{min} / 1.73 \mathrm{~m} \wedge 2\end{array}$} & \multicolumn{3}{|l|}{$\begin{array}{l}\text { Proteinuria } \\
m g / m \wedge 2 / \text { die }\end{array}$} \\
\hline & T0 & $\mathrm{T} 14$ & $p<$ & T0 & T14 & $p<$ \\
\hline SFK & $128.89 \pm 32.24$ & $118.51 \pm 34.45$ & NS & $85.14 \pm 83.13$ & $159.03 \pm 234.66$ & NS \\
\hline aSFK & $109.41 \pm 33.71$ & $100.72 \pm 33.49$ & NS & $61.35 \pm 17.15$ & $140.52 \pm 122.26$ & NS \\
\hline CSFK & $126.60 \pm 34.98$ & $103.76 \pm 46.49$ & NS & $106.30 \pm 111.78$ & $147.15 \pm 247.46$ & NS \\
\hline
\end{tabular}

SFK all solitary functioning kidney patients; aSFK acquired type; cSFK: congenital type

GFR and Proteinuria at TO and T14: aSFK vs CSFK, SFK vs aSFK, SFK vs CSFK: $p$ NS 
Table 2 Blood pressure at time of diagnosis (TO) and after 14 years follow-up (T14)

\begin{tabular}{llll}
\hline & T0 & T14 & T0 vs T14 p< \\
\hline SFK with BP > 90\%thile & $12 / 55(22 \%)$ & $42 / 55(76.4 \%)$ & 0.0001 \\
aSFK & $5 / 17(29 \%)$ & $14 / 17(82.4 \%)$ & 0.005 \\
CSFK & $7 / 38(18 \%)$ & $28 / 38(73.7 \%)$ & 0.0001 \\
PreHyp-SFK & $6 / 55(10.9 \%)$ & $22 / 55(40 \%)$ & 0.0008 \\
PreHyp-aSFK & $3 / 17(17.6 \%)$ & $5 / 17(29.4 \%)$ & NS \\
PreHyp-cSFK & $3 / 38(7.9 \%)$ & $17 / 38(44.7 \%)$ & 0.0005 \\
Hyp-SFK & $6 / 55(11 \%)$ & $20 / 55(36.4 \%)$ & 0.003 \\
Hyp-aSFK & $2 / 17(12 \%)$ & $9 / 17(52.9 \%)$ & 0.025 \\
Hyp-cSFK & $4 / 38(10 \%)$ & $11 / 38(29 \%)$ & NS \\
\hline
\end{tabular}

SFK all solitary functioning kidney patients; aSFK acquired type; cSFK congenital type

PreHyp-aSFK: acquired solitary functioning kidney patients with prehypertension

PreHyp-cSFK: congenital solitary functioning kidney patients with prehypertension

Hyp-aSFK: acquired solitary functioning kidney patients with hypertension Hyp-cSFK: congenital solitary functioning kidney patients with hypertension

without reduction in glomerular filtration rate or increase of serum creatinine levels.

However the higher incidence of subjects with hypertension as shown in our study, albeit higher, is in agreement with those of the KIMONO study (21\%) [21, 22]. We believe that the higher hypertension percentage we found, in our study, could be due to the use of ABPM method of measurement, actually representing the most reliable technic of measurement of blood pressure in children $[5,14]$. In our study, contrary to other authors [23], we did not detect any cases of masked hypertension. However, we detected a higher number of hypertensive subjects, possibly because of the longer period of follow-up. We suspect that a number of children developed masked hypertension first and by the time they reached the age when we could use ABPM they had progressed to hypertension.

We measured the blood pressure with ABPM at T0 and T14 whenever feasible, i.e., when the child height is $\geq 120 \mathrm{~cm}$. This was always the case with SFK patients acquired type, but SFK patients congenital type where first observed at a very young age, and ABPM could not be used at T0. It was therefore necessary to compare the IV Report classification [15] with the updated recommendations for the standard assessment of ABPM in children and adolescents [17].). We should observe that data offered by office blood pressure alone do not diverge from the integration of office blood pressure and ABPM. We still support the use of ABPM as it detects white coat hypertension and masked hypertension, and it is the best available tool to assess the effects of antihypertension therapy in the 24 h time span. Nevertheless, the peculiarity of our results is in the classification of the blood pressure status of the subjects who develop values higher than the 90th centile. Up to $36.40 \%$ of patients developed hypertension and up to $40 \%$ prehypertension; while the former was mostly observed in the acquired SFK group and the latter in the congenital SFK.

Our data differs from a later report by Westland et al. [23] showing a $26 \%$ incidence of hypertension and $11 \%$ pre-hypertension in children with SFK with a non-statistical significant different distribution between acquired and congenital types of SFK.

Furthermore, our findings have distinct characteristics compared to the reports by Seeman et al. [7]. This study reported hypertension only in CSFK that developed renal scars. On the contrary our finding support hypertension to be more frequently found in association with aSFK; a group of patients who developed a lesser number of renal scars. This observation seems in accordance with a report by Jaoudé et al. suggesting that compensation of renal metabolism by the residual kidney may be more difficult in cases of nephrectomy following trauma [24] and this could account for the higher development of hypertension. We should not underestimate the influence of renal scars on the onset of hypertension. In fact, contrary to acquired solitary functioning kidneys, in the congenital group the number of hypertensive subjects with renal scars increases significantly from T0 to T14. It is worth noting that children with vesicoureteral reflux were excluded from this study. Also of interest, Maheen et al. [25] observed that $21 \%$ of otherwise healthy children with newly diagnosed hypertension had renal scars. Seeman et al. [7] recommend a close follow-up for hypertension for all children with renal scars in SFK.

Current study also highlights the presence of prehypertension in $40 \%$ of the cases; a condition that we believe requires a close observation. Since prehypertension state is prone to develop into hypertension [26, 27], its early detection in SFK children should be taken into consideration. Therefore adequate renal protective treatment and blood pressure control in these patients should be promptly instituted [28]. Moreover, the increase in blood pressure should be also treated with an increase of sport activity; since it tends to improve the cardiorespiratory fitness in children with SFK [29] and kidney transplantation [30].

\section{Conclusions}

In view of the significant increase in blood pressure over a 14 year follow-up, we suggest prolonged mandatory follow-up of blood pressure every 6 months in children with both acquired and congenital SFK; in view of the higher incidence of prehypertension and hypertension that we found in this population, we consider it more appropriate than the yearly control suggested by Westland et al. [23]. The screening for 
hypertension should be conducted by clinic blood pressure as well as by ABPM.

Specific attention should be given to the screening of patients for suspect prehypertension; as these children could definitely benefit from simple changes in life style and the early institution of an adequate medical therapy, that effectively prevent the clinical consequences and contrast the progression to hypertension [8].

\section{Abbreviations}

ABPM: Ambulatory blood pressure monitoring; aSFK: Acquired solitary functioning kidney; CAKUT: Congenital anomalies of the kidney and urinary tract; CSFK: Congenital solitary functioning kidney; ESRD: End stage renal disease; GFR: Glomerular filtration rate; Hyp: Hypertension; PreHyp: Prehypertension; SFK: Solitary functioning kidney

\section{Acknowledgements}

Not applicable.

\section{Funding}

Nothing to declare.

\section{Availability of data and materials}

Please contact author for data requests.

\section{Authors' contributions}

LR participated in the design of the study, performed the statistical analysis and drafted the manuscript. PS monitored data collection for the whole trial. FR carried out the statistical analysis. VG carried out data collection. VG helped in performing the statistical analysis and helped to draft the manuscript. SS carried out data collection. AM carried out data collection. EM participated in the coordination and helped to draft the manuscript. All authors read and approved the final manuscript.

\section{Competing interests}

The authors declare that they have no competing interests.

\section{Consent for publication}

Not applicable.

\section{Ethics approval and consent to participate}

For each child informed consent was obtained from both parents and the study protocol conformed to the ethical guidelines of the 1975 Declaration of Helsinki as revised in 2000. The study was approved by the ethical committee in our institutions.

\section{Publisher's Note}

Springer Nature remains neutral with regard to jurisdictional claims in published maps and institutional affiliations.

\section{Author details}

${ }^{1}$ Pediatric Department, Pediatric Nephrology Unit, Sapienza University of Rome, Viale Regina Elena 324, 00161 Rome, Italy. ${ }^{2}$ General Pediatrics and Pediatric Acute and Emergency Unit, Policlinico-Vittorio-Emanuele University Hospital, Catania, Italy. ${ }^{3}$ DiBiC-Biomedical and Clinic Science Department, "Luigi Sacco" - University of Milan, Milan, Italy.

Received: 6 September 2016 Accepted: 13 April 2017

Published online: 27 April 2017

\section{References}

1. Brenner BM, Lawler EV, Mackenzie HS. The hyperfiltration theory: a paradigm shift in nephrology. Kidney Int. 1996;49:1774-7.

2. Brenner BM, Hostetter TH, Olson JL, Rennke HG, Venkatachalam MA. The role of glomerular hyperfiltration in the initiation and progression of diabetic nephropathy. Acta Endocrinol Suppl (Copenh). 1981;242:7-10.

3. Brenner BM, Meyer TW, Hostetter TH. Dietary protein intake and the progressive nature of kidney disease: the role of hemodynamically mediated glomerular injury in the pathogenesis of progressive glomerular scle- rosis in aging, renal ablation, and intrinsic renal disease. $\mathrm{N}$ Engl J Med. 1982;307:652-9.

4. Siomou E, Giapros V, Papadopoulou F, Pavlou M, Fotopoulos A, Siamopoulou A. Growth and function in childhood of a normal solitary kidney from birth or from early infancy. Pediatr Nephrol. 2014;29:249-56.

5. Dursun H, Bayazit AK, Cengiz N, Seydaoglu G, Buyukcelik M, Soran M, Noyan A, Anarat A. Ambulatory blood pressure monitoring and renal functions in children with a solitary kidney. Pediatr Nephrol. 2007;22:559-64.

6. Shirzai A, Yildiz N, Biyikli N, Ustunsoy S, Benzer M, Alpay H. Is microalbuminuria a risk factor for hypertension in children with solitary kidney? Pediatr Nephrol. 2014;29:283-8.

7. Seeman T, Patzer L, John U, John U, Dusek J, Vondrák K, Janda J, Misselwitz J. Blood pressure, renal function, and proteinuria in children with Unilateral Renal Agenesis. Kidney Blood Press Res. 2006:29:210-5.

8. Lubrano R, Travasso E, Raggi C, Guido G, Masciangelo R, Elli M. Blood pressure load, proteinuria and renal function in pre-hypertensive children. Pediatr Nephrol. 2009;24:823-31.

9. Mulligan JS, Blue PW, Hasbargen JA. Methods for measuring GFR with technetium-99 m-DTPA: an analysis of several common methods. J Nucl Med. 1990:31:1211-9.

10. Ataei N, Madani A, Esfahani ST, Kejbafzadeh A, Ghaderi O, Jalili S, Sharafi B. Screening for vesicoureteral reflux and renal scars in siblings of children with known reflux. Pediatr Nephrol. 2004;19:1127-31.

11. Stevens PE, Levin A, for the kidney Disease Improving Global Outcomes Chronic Kidney Disease Guideline Development Work Group Members. Evaluation and management of chronic kidney disease: synopsis of the kidney disease: improving global outcomes 2012 Clinical practice guidelines. Ann Intern Med. 2013;158:825-30.

12. Hogg RJ, Furth S, Lemley KV, Portman R, Schwatz GJ, Balk E, Lau J, Levin A, Kausz AT, Eknoyan G, Levely AS. National kidney foundation's kidney disease outcomes quality initiative clinical practice guidelines for chronic kidney disease in children and adolescents: evaluation, classification, and stratification. Pediatrics. 2003;111:1416-21.

13. Hogg RJ, Portman RJ, Milliner D, Lemley KV, Eddy A, Ingelfinger J. Evaluation and management of proteinuria and nephrotic syndrome in children: recommendations from a pediatric nephrology panel established at the national kidney foundation conference on proteinuria, albuminuria, risk, assessment, detection and elimination (PARADE). Pediatrics. 2000;105:1242-9.

14. Lubrano R, Paoli S, Spiga S, Falsaperla R, Vitaliti G, Gentile I, Elli M. Impact of ambulatory blood pressure monitoring on the diagnosis of hypertension in children. J Am Soc Hypertens. 2015;9:780-4.

15. National High Blood Pressure Education Program Working Group on High Blood Pressure in Children and Adolescents. The Fourth Report on the diagnosis, evaluation, and treatment of high blood pressure in children and adolescents. Pediatrics. 2004;114:555-76.

16. Flynn JT. Neonatal hypertension: diagnosis and management. Pediatr Nephron. 2000;14:332-41.

17. Flynn JT, Daniels SR, Hayman LL, Maahs DM, McCrindle BW, Mitsnefes M, Zachariah JP, Urbina EM, American Heart Association Atherosclerosis, Hypertension and Obesity in Youth Committee of the Council on Cardiovascular Disease in the Young. American Heart Association Atherosclerosis, Hypertension and Obesity in Youth Committee of the Council on Cardiovascular Disease in the Young. Update: ambulatory blood pressure monitoring in children and adolescents: a scientific statement from the American Heart Association. Hypertension. 2014;63:1116-35.

18. ESH/ESC Task Force for the Management of Arterial Hypertension. 2013 Practice guidelines for the management of arterial hypertension of the European Society of Hypertension (ESH) and the European Society of Cardiology (ESC): ESH/ESC Task Force for the Management of Arterial Hypertension. J Hypertens. 2013;31(10):1925-38.

19. World Medical Association. Declaration of Helsinki: ethical principles for medical research involving human subjects. JAMA. 2000;284:3043-5.

20. Peco-Antić A, Paripović D, Kotur-Stevuljević J, Stefanović A, Šćekić G, Miloševski-Lomić $\mathrm{G}$. Renal functional reserve in children with apparently normal congenital solitary functioning kidney. Clin Biochem. 2012;45:1173-7.

21. Westland R, Kurvers RA, van Kijk JA, Schreuder MF. Risk factors for renal injury in children with a solitary functioning Kidney. Pediatrics. 2013:131:e478-e 485.

22. Westland R, Schreude MF, Bökenkamp A, Spreeuwenberg MD, van Wijk JAE. Renal injury in children with a solitary functioning kidney-the KIMONO study. Nephrol Dial Transplant. 2011;26:1533-41. 
23. Westland R, Schreuder MF, van der Lof DF, Vermeulen A, Dekker-van der Meer IMJ, Bökenkamp A, van Wijk JAE. Ambulatory blood pressure monitoring is recommended in the clinical management of children with a solitary functioning kidney. Pediatr Nephrol. 2014;29:2205-11.

24. Jaoudé PA, Dubourg L, Bacchetta J, Berthiller J, Ranchin B, Cochat P. Congenital versus acquired solitary kidney: is the difference relevant? Nephrol Dial Transplant. 2011;26:2188-94.

25. Maheen A, Eggleston D, Kapur G, Jain A, Valentini RP, Mattoo TK. Dimercaptosuccinic acid (DMSA) renal scan in the evaluation of hypertension in children. Pediatr Nephrol. 2008;23:435-8.

26. Redwine KM, Acosta AA, Poffenbarger T, Portman RJ, Samuels J. Development of hypetension in adolescent with prehypertension. J Pediatr. 2012;160:98-103.

27. Redwine KM, Daniels SR. Prehypertension in adolescents: risk and progression. J Clin Hypertens (Greenwich). 2012;14:360-4.

28. Lubrano R, Soscia F, Elli M, Ventriglia F, Raggi C, Travasso E, Scateni S, Di Maio V, Versacci P, Masciangelo R, Romero S. Renal and cardiovascular effects of angiotensin-converting enzyme inhibitor plus angiotensin II receptor antagonist therapy in children with proteinuria. Pediatrics. 2006; 118:e833-8.

29. Tancredi G, Lambiase C, Favoriti A, Ricupito F, Paoli S, Duse M, De Castro G, Zicari AM, Vitaliti G, Falsaperla R, Lubrano R. Cardiorespiratory fitness and sports activities in children and adolescents with solitary functioning kidney. Ital J Pediatr. 2016:42:43.

30. Lubrano R, Tancredi G, Bellelli E, Gentile I, Scateni S, Masciangelo R, De Castro G, Versacci P, Elli M. Influence of physical activity on cardiorespiratory fitness in children after renal transplantation. Nephrol Dial Transplant. 2012; 27:1677-81.

\section{Submit your next manuscript to BioMed Central and we will help you at every step:}

- We accept pre-submission inquiries

- Our selector tool helps you to find the most relevant journal

- We provide round the clock customer support

- Convenient online submission

- Thorough peer review

- Inclusion in PubMed and all major indexing services

- Maximum visibility for your research

Submit your manuscript at www.biomedcentral.com/submit 